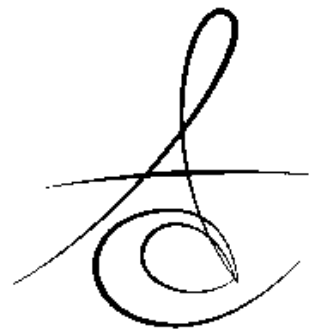

\title{
İKİ SELF-ETCH BONDING SİSTEMİN BİYOUYUMLULUKLARININ VE BAĞLANMA DAYANIMLARININ DEĞERLENDİRİLMESİ
}

\section{EVALUATION OF BIOCOMPATIBILITY AND BOND STRENGTHS OF TWO SELF-ETCH ADHESIVE SYSTEMS}

Yrd. Doç. Dr. H. Esra ÜLKER*

Dt. Ali İhsan ERKAN*
Dt. M. Tuğba TUNÇDEMİR*

Yrd. Doç. Dr. Meral ARSLAN MALKOÇ**

Yrd. Doç. Dr. Nevin ÇOBANOĞLU*

Makale Kodu/Article code: 1267

Makale Gönderilme tarihi: 20.08.2013

Kabul Tarihi: 22.10.2013

\section{ÖZET}

Amaç: Bu çalışmanın amacı iki farklı self-etch adeziv sistemin [Clearfil SE Bond (CSE) ve G-Bond (GB)] biyouyumluluk ve dentine bağlanma dayanımlarının değerlendirilmesidir.

Gereç - Yöntem: Çalışma için 8 adet çekilmiş çürüksüz insan üçüncü azı dişi kullanıldı. Tüm dişlerin oklüzal yüzeyleri düz bir dentin yüzeyi elde etmek için dişin uzun eksenine dik olacak şekilde aşındırıldı. Dişler rastgele 2 gruba ayrıldı ve dişlerin oklüzal yüzeylerine adeziv sistemler üretici firmanın önerileri doğrultusunda uygulandıktan sonra Gradia Direct kompozit ile restore edildi. Örnekler, bağlantı ara yüzeyine dik olacak şekilde kesildi (bağlantı alanı: $1 \mathrm{~mm}^{2}$ ) ve her grup için 15 çubuk elde edildi. Çubuklar daha sonra mikrogerilim bağlanma testine (Microtensile tester, Bisco, Schaumburg, IL, ABD) tabi tutuldu. Veriler tek yönlü varyans analizi kullanılarak analiz edildi. Biyouyumluluğun değerlendirilmesi için agar overlay testi yapıldı. 24 saat sonra inverted mikroskopla hücre dekolarizasyon zonu ve hücre lizis skorları tespit edildi. Veriler Kruskal wallis ve Mann withney $U$ testi ile değerlendirildi.

Bulgular: CSE (23.5 MPa), GB (18.9 MPa) dan daha yüksek bağlanma dayanımı gösterdi $(p<0.05)$. Agar overlay testi sonuçlarına göre ise her iki adeziv de pozitif kontrol grubundan daha az hücre lizisi ve dekolarizasyon zonu gösterdi $(p<0.001)$.

Sonuç: Kullanılan bonding sistemlerin sitotoksisiteleri arasında istatistiksel olarak önemli bir fark olmadığı için daha yüksek bağlanma dayanımına sahip olan adeziv sistem (CSE) klinik olarak tercih edilebilir.

Anahtar Kelimeler: Biyouyumlu materyaller, dentin yapıştırma ajanları, sitotoksisite testleri.

\section{ABSTRACT}

Objectives: The aim of this study was to evaluate the biocompatibility and dentin bond strengths of two different self-etch adhesive systems[Clearfil SE Bond (CSE) and G-Bond (GB)].

Materials and methods: Non-carious 8 extracted human third molar teeth were used in this study. The occlusal surfaces of all teeth were ground perpendicular to the long axis of each tooth to expose a flat dentin surface. The teeth were divided into two groups and adhesive systems were applied according to the manufacturer's instructions to the oclusal surfaces of the teeth and restored with Gradia Direct composite resin. The samples were sectioned perpendicular to the adhesive interface to produce sticks (adhesive area: $1 \mathrm{~mm}^{2}$ ) and fifteen sticks were obtained for each group. All sticks submitted to microtensile bond strength test (Microtensile tester, Bisco, Schaumburg, IL, ABD). Data were analyzed using one-way varyans analysis ANOVA. An agar overlay test was used for the cytotoxicity evaluation. Cytotoxicity was examined by measuring the zones of cell decolorization and evaluating cell lysis by an inverted microscope after 24 hours. Data were analyzed using Kruskal wallis and Mann withney $U$ test.

Results: CSE showed higher dentin bond strength mean (23.5 MPa) than GB (18.9 MPa) $(p<0.05)$. Both bonding systems showed lower lysis scores than positive control material $(p<0.001)$.

Conclusions: The bonding agent which is higer bond strength may be prefered for a long-lasting restoration since there is no a statistically significant difference between toxicity of used two bonding systems.

Key Words: Biocompatible materials, dentin bonding agents, cytotoxicity tests

* Selçuk Üniversitesi, Dişhekimliği Fakültesi, Restoratif Diş Tedavisi A.D., Konya, Türkiye

**İnönü Üniversitesi, Dişhekimliği Fakültesi, Protetik Diş Tedavisi A.D, Malatya, Türkiye 


\section{GİRIS}

Modern diş hekimliğinde sağlıklı diş dokusunun korunması ve hastaların estetik beklentilerinin karşılanması amacı ile hekimler ve araştırmacılar daha estetik, uzun ömürlü ve daha fonksiyonel materyaller geliştirmeye yönelmiştir. ${ }^{1}$ Böylelikle çiğneme kuvvetlerine ve polimerizasyon büzülmesinin oluşturduğu streslere karşı koyabilen ve mikrosızıntıya dirençli, sekonder çürük oluşumunun en aza indirgendiği restorasyonların elde edilmesi amaçlanmıştır. ${ }^{2}$

Günümüzde geliştirilen adeziv sistemler ile diş dokusundan çok fazla madde kaldırılmadan başarılı tedaviler yapılabilmektedir. Adeziv sistemlerle mineye ve dentine mikromekanik ve kimyasal yolla bağlanabilmesine rağmen klinik uygulama esnasında teknik hassasiyete neden olan çoklu uygulama aşamaları gerektirmektedirler. ${ }^{1,2}$ Bu nedenle klinisyenin profesyonelliğiyle orantılı olarak diş dokusuna bağlanmada değişik sonuçlar gözlenebilmektedir. Son zamanlarda uygulama prosedürleri daha basit olan adeziv sistemler geliştirilerek uygulamaya bağı başarısızlıklar en aza indirgenmeye çalışılmaktadır. ${ }^{1}$

Klinikte başarılı sonuçlar gösterebilmesi için dental adezivlerin iyi fiziksel özellikler göstermesinin yanı sıra dentine bu kadar yakın temasta olan adeziv sistemlerin biyouyumluluğu da çok önemlidir. Biyouyumluluk, bir biyomateryalin canlı dokularla temas halinde iken vücudun yumuşak ve sert dokularında, lokal veya sistemik toksisite, alerji, mutajenik ve karsinojenik etkiler gibi "doku reaksiyonları" oluşturmaması olarak ifade edilir. ${ }^{3}$

Diş hekimliğinde kullanılan malzemelerin biyolojik olarak incelenmesinde çok sayıda teknik kullanımaktadır: in vitro deneyler, in vivo hayvan deneyleri ve insanlarda klinik çalışmalar olmak üzere üç basamakta yürütülmektedir. In vitro hücre kültürü testleri kontrol edilebilen, tekrarlanabilen , daha çabuk sonuç alınabilen , uygulaması kolay ve maliyeti ise daha az olan testlerdir. ${ }^{4}$ Hayvan ve insan çalışmalarında karşılaşılan etik problemler in vitro deneylerde yoktur. Ancak sonuçlarının in vivo koşulların sonuçları ile bağlantısının kurulması güçtür, vücutta materyale karşı çok kompleks biyolojik cevaplar gelişir. ${ }^{5}$

Ağız ortamında, materyal ve pulpa dokusu arasında hidrofobik monomerlerin pulpaya geçişini önleyen bir dentin bariyer mevcuttur. İndirekt hücremateryal kontağı testlerinde ise agar, agaroz ${ }^{6}$ ve selüloz asetat filtre ${ }^{7}$ gibi bariyerler kullanılmıştır. Böylece, hücreler bakteriyel kontaminasyon veya mekanik hasardan korunurken, dolgu maddeleri ile hücreleri birbirinden ayrılabilmektedir. ${ }^{4}$ Ancak, bu tür bariyerlerin tam olarak in vivo koşulları taklit edemeyeceğini bildiren görüşler de mevcuttur., ${ }^{7,8}$

$\mathrm{Bu}$ çalışmanın amacı klinikte yaygın olarak kullandığımız ve kompozit dolguların diş sert dokularına bağlantısını sağlayan iki self-etch adeziv sistemin dentine bağlanma dayanımlarının ve agar-over lay metodu kullanılarak sitotoksisitelerinin değerlendirilmesidir.

\section{GEREÇ ve YÖNTEM}

\section{Mikrogerilim Bağlanma Dayanımı Deneyinin Uygulanması}

Çalışma için 8 adet çekilmiş çürüksüz insan üçüncü azı dişi kullanıldı. Tüm dişlerin oklüzal yüzeyleri düz bir dentin yüzeyi elde etmek için dişin uzun eksenine dik olacak şekilde aşındırıldı. Dişler rastgele 2 gruba ayrıldı ve ardından dişlerin oklüzal yüzeylerine bir gruba Clearfil SE Bond (Kuraray, Kurashki, Japonya) ve diğer gruba G-Bond (GC, Tokyo, Japonya) dentin bağlayıcı sistemleri üretici firmanın önerileri doğrultusunda uygulandı. Daha sonra diş yüzeyleri Gradia Direct (GC, Tokyo, Japonya) kompozit ile restore edildi. Restore edilen dişler 24 saat suda bekletildikten sonra kökleri kuronlarından (sementmine birleşimin yaklaşık 2-3 mm altından) düşük hızda çalışan elmas bir separe ile (Isomet; Buehler, Lake Bluff, IL, ABD) su soğutması altında ayrıldı. Her bir örnek akrilik bloğa $(3 \times 2 \mathrm{~cm})$ sirkolant ile sabitlendi. Akrilik blok kesme cihazına (Isomet 1000; Buehler, Precision Saw, Lake Bluff, IL, ABD) yerleştirildi ve düşük hızda çalışan elmas bir separe ile (Isomet; Buehler, Lake Bluff, IL, ABD) kesilerek $1 \pm 0.03 \mathrm{~mm}^{2}$ lik kare kesitli test çubukları elde edildi. Her örneğin pulpa odasının üzerindeki merkezi dentin yüzey alanından elde edilen 3-4 adet test çubuğu kullanılmak üzere ayrıldı. Böylece her grupta her bir self-etch adeziv sistem için toplam 15 adet test çubuğu elde edilmiş oldu. Test çubukları elde edilmesi işlemleri sırasında test öncesi başarısızlık gösteren örnekler kaydedildi. Ancak bu örnekler sonuçlara dahil edilmedi. $^{2}$

Test çubukları mikrogerilim test cihazına (Microtensile tester, Bisco, Schaumburg, IL, ABD) siyanoakrilat bir adeziv (Model repair II pink, Dentsply 
sankin, Ohtawara, Japonya) ile her iki ucundan yapıştırıldı (Resim 1). Test cihazının yükleme hızı (crosshead speed) $1 \mathrm{~mm} / \mathrm{dk}$ ve yükleme kuvveti 100 Newton olarak belirlendi. Bir dijital mikrometreyle (Mitutoyo, Japonya) test çubuklarının kenar uzunlukları ölçülerek bağlanma yüzey alanı hesaplandı. Newton cinsinden elde edilen sonuçlar bağlanma yüzey alanına bölünerek MPa'a çevrildi. Veriler istatistiksel olarak tek yönlü varyans analizi (ANOVA) ile analiz edildi.

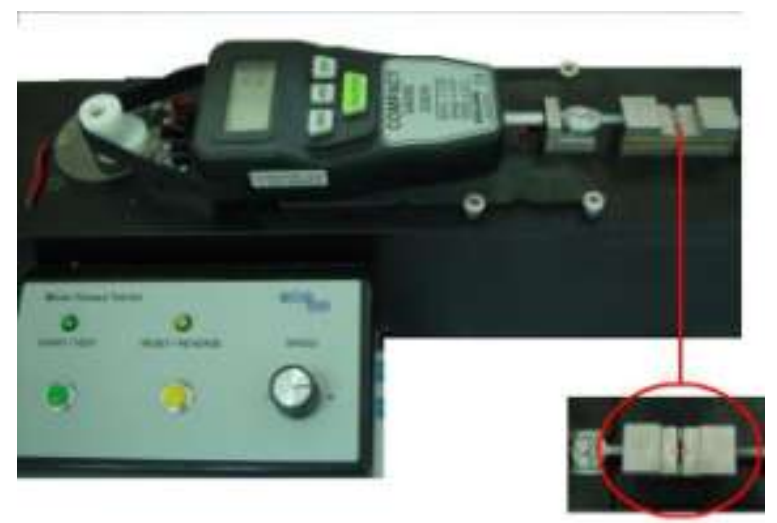

Resim 1. Mikrogerilim deneyi düzeneği

\section{Agar Overlay Testi}

Çalışmada L929 fare fibroblast hücreleri (Mouse C3/An connective tissue, 92123004, Şap Enstitüsü, Ankara, Türkiye) kullanıldı. Hücreler $\% 10$ New Born Calf Serum (Leonorenstr, Berlin), \%5 penisilin/ streptomisin (Biological Industries, Haemek, İsrail) içeren besi ortamı (Basal Medium Eagle Earle, Leonorenstr, Berlin) içerisinde \%5 $\mathrm{CO}_{2}{ }^{\prime} \mathrm{li}$ ortamda, $37^{\circ} \mathrm{C}$ 'de inkübe edildi. Hücreler deney kaplarında yeterli doluluğa erişince \%0.25 trypsin (Biological Industries, Haemek, İsrail) ile kaldırıldı ve $25 \times 10^{3}$ hücre/ml olacak şekilde $100 \mathrm{~mm}$ 'lik $\left(60 \mathrm{~cm}^{2}\right)$ hücre kültürü petrilerine (Corning, New York, ABD) alınarak $37^{\circ} \mathrm{C}^{\prime} \mathrm{de}, \% 5 \mathrm{CO}_{2}$ ve \%95 hava karışımlı bir ortamda 24 saat inkübe edildi. İnkübasyon süresi sonunda hücrelerin besi ortamları uzaklaştırılarak, üzerleri \%3' lük agar içeren medium ile kaplandı ve hücreler $\% 0.01^{\prime}$ lik nötral red solüsyonu ile boyandı. Bonding materyaller $5 \mathrm{~mm}^{\prime}$ lik kağıt diskler üzerine üretici firma tavsiyelerine göre uygulandı. Her petride 2 örnek olacak şekilde diskler agar üzerine yerleştirildi ve her grup için toplam 5 petri kullanıldı $(n=10)$. Pozitif kontrol olarak vitrebond cam iyonomer siman (3M Medica $\mathrm{GmbH}$, Broken, Almanya) steril ortamda üretici firmanın önerileri dikkate alınarak silindirik şekilli steril standart teflon halkalar $(2 \times 5 \mathrm{~mm})$ içerisinde hazırlandı ve agar üzerine yerleştirildi.

Örnekler 24 saat karanlık ortamda inkübe edildi. Sağlıklı hücrelerin sitoplazması nötral-redi alarak kırmızıya boyandı. Test materyallerinden hücre lizisine sebep olan toksik moleküller agardan diffüze olarak, hücre zarını etkileyip sitoplazmanın dağılmasına ve hücrelerin canlılığını yitirmesine yol açtı. Böylece hücrelerin membran permeabilizasyonu sonucu nötral red çözündü. Sağlıklı hücreler içerisinde nötral red bulundurduğundan kırmızı renkte görünürken, membranı bozularak lizise uğrayan hücreler daha açık renkte görüldü (Resim 2).

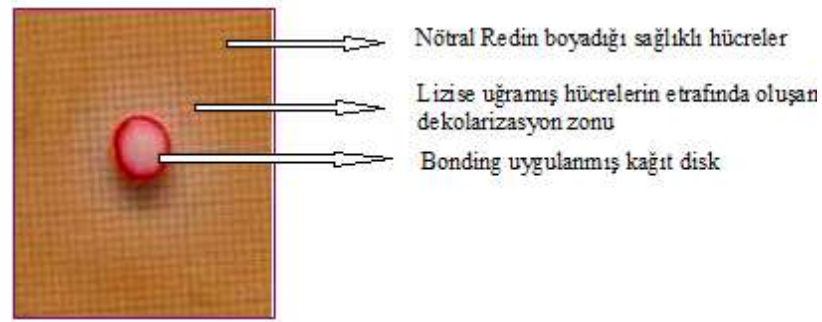

Resim 2. Agar Overlay deneyinde gözlenen dekolarizasyon zonu görüntüsü

Yirmi dört saat sonunda inverted mikroskopla test örneklerinin etrafında gözlenen hücre dekolarizasyon zonu ve hücre lizis skorları (Tablo 2) tespit edildi. ${ }^{6}$ Sitotoksisiteleri ISO 7405'e göre değerlendirildi. Sonuçlar Kruskal-Wallis ve Mann-Whitney $U$ testleri kullanılarak istatistiksel olarak değerlendirildi.

Tablo 1. Dentin Bağlayıcı sistemlerin lot numaraları, içerikleri ve üretici firmaları.

\begin{tabular}{|c|c|c|}
\hline $\begin{array}{l}\text { Dentin Bağlayıcı } \\
\text { Sistem }\end{array}$ & İçerik & Üretici/ lot \\
\hline Clearfil SE Bond & $\begin{array}{l}\text { Primer: bisphenol A, } \\
\text { MDP, HEMA, hidrofilik } \\
\text { dimetakrilat, kamforokinon, } \\
\text { su } \\
\text { Bond: MDP, bis-GMA, HEMA, } \\
\text { hidrofobik dimetakrilat, } \\
\text { kamforokinon }\end{array}$ & $\begin{array}{l}\text { Kuraray Med. } \\
\text { Inc., Japonya } \\
\text { 01153A- } \\
01729 \mathrm{~A}\end{array}$ \\
\hline G-Bond & $\begin{array}{l}\text { 4-MET, UDMA, silica, fosforik } \\
\text { asit, ester monomer, } \\
\text { aseton, fotobaşlatıcı. }\end{array}$ & $\begin{array}{l}\text { GC } \\
\text { Corporation, } \\
\text { Japonya } \\
1011131 \\
\end{array}$ \\
\hline
\end{tabular}


Tablo 2. İnverted mikroskopla test örneklerinin etrafında gözlenen hücre dekolarizasyon zonu ve hücre lizisi indeksi skorları.

\begin{tabular}{|c|c|c|}
\hline Skor & $\begin{array}{ll}\text { Dekolarizasyon } & \text { Zonu } \\
\text { Indeks Skorları } & \\
\end{array}$ & Lizis İndeks Skorları \\
\hline $\mathbf{0}$ & Yok & Yok \\
\hline 1 & Sadece diskin altında & \%20 den daha az \\
\hline 2 & $\begin{array}{l}\text { Diskin etrafında en fazla } 5 \\
\mathrm{~mm}\end{array}$ & $\% 20-40$ arası \\
\hline 3 & $\begin{array}{l}\text { Diskin etrafında en fazla } 5 \text { - } \\
10 \mathrm{~mm} \text { arası }\end{array}$ & $\begin{array}{l}\text { \%60 dan daha az \%40 } \\
\text { dan daha fazla }\end{array}$ \\
\hline 4 & $\begin{array}{l}\text { Diskin etrafında } 10 \mathrm{~mm} \text { den } \\
\text { daha fazla }\end{array}$ & $\% 60-80$ arası \\
\hline 5 & $\begin{array}{l}\text { Tüm kültür petrisi dekolarize } \\
\text { olmuş }\end{array}$ & $\% 80$ den daha fazla \\
\hline
\end{tabular}

\section{BULGULAR}

Mikrogerilim bağlanma dayanımı test sonuçları Grafik 1' de gösterilmiştir. CSE ve GB gruplarının bağlanma dayanımları sırası ile $23.5 \mathrm{MPa}$ ve $18.9 \mathrm{MPa}$ olarak bulunmuştur. Bonding sistemlerin bağlanma dayanımları arasında istatistiksel olarak anlamlı farklılık vardır $(p<0.05)$.

Agar overlay sitotoksisite test sonuçları Grafik 2 ve 3' de gösterilmiştir. Agar overlay testi sonuçlarına göre ise CSE ve GB grupları pozitif kontrol grubundan (Vitrebond) daha az hücre lizisi ve dekolarizasyon zonu gösterdi $(p<0.001)$. Dekolarizasyon zonu ve lizis indeksi skorlarına göre her iki adeziv de pozitif kontrol grubundan anlamlı derecede farklı bulundu $(p<0.001)$. Dentin bağlayıcı sistemler birbirleri ile karşılaştırıldığında iki grup arasında anlamlı bir fark gözlenmedi $(p>0.05)$.

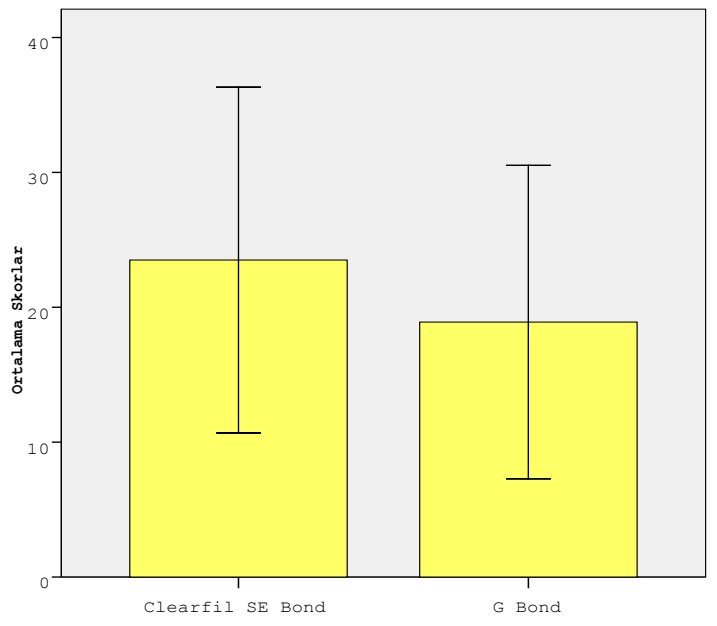

Grafik 1: Ortalama mikrogerilim bağlanma dayanımları.

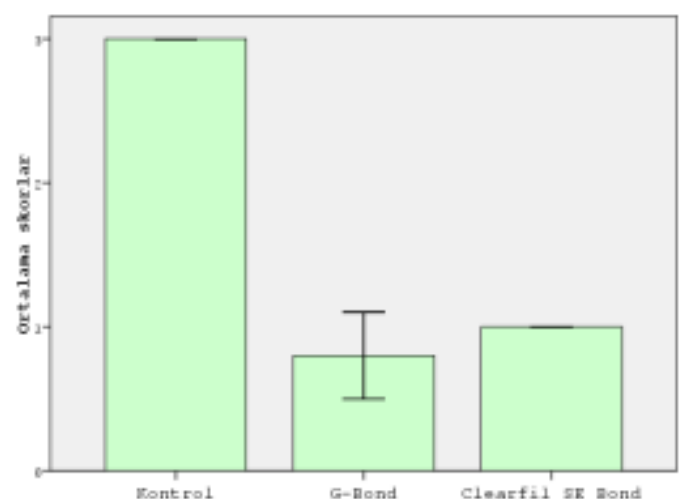

Grafik 2. Ortalama lizis indeks skorları

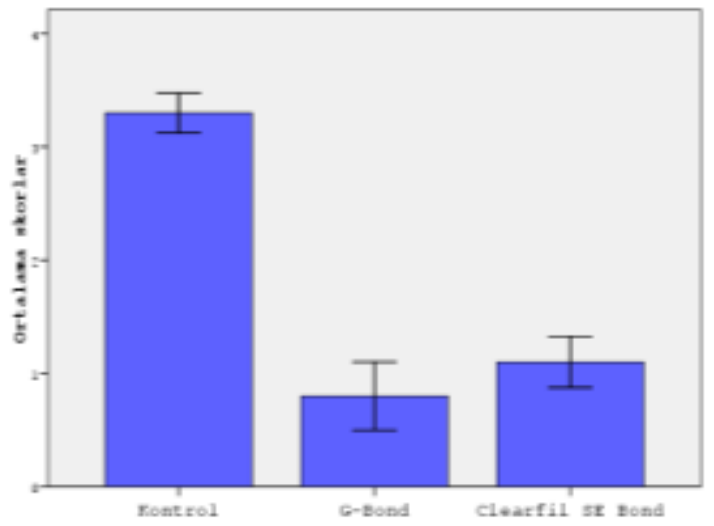

Grafik 3. Ortalama zone indeks skorları

\section{TARTIŞMA}

Bu çalışmada biri tek diğeri iki aşamalı olan iki self-etch adeziv sistem kullanıldı. İki aşamalı CSE'nin dentine mikrogerilim bağlanma dayanımının tek aşamalı GB' a göre daha iyi olduğu görüldü (Grafik 1). Bizim araştırmamızla uyumlu olarak daha önce yapılan araştırmalarda da CSE'nin dentine bağlanma dayanımının tek aşamalı GB'a göre daha yüksek olduğu belirtilmiştir. ${ }^{9,-1}$ Self-etch adeziv sistemlerin kimyasal içerikleri bu sistemlerin performansları üzerinde önemli bir etkiye sahiptir. CSE fonksiyonel monomer olarak 10-Methacryloyloxydecyl dihydrogen phosphate (MDP) ve GB ise 4-META içermektedir.10 MDP hibrit tabaka içinde kalan hidroksiapatit ile kimyasal bir etkileşime girerek mikromekanik bağlantıya ek olarak kimyasal bağlantı sağlayan fonksiyonel bir monomerdir. ${ }^{12}$

Yoshida ve ark'da çalışmalarında 10-MDP için bağlanma dayanımının 4-META için olandan daha yüksek olduğunu rapor etmişlerdir. ${ }^{12}$ Ayrıca Chiaraput

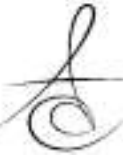


ve ark. çalışmalarında, 10 MDP içeren CSE ve Clearfil $\mathrm{S}^{3}$ bondun bağlanma dayanımını GB dan daha yüksek bulmuşlar ve bu sonucun sebebinin 10-MDP nin üstün özellikleriyle ilgili olabileceğini belirtmişlerdir. ${ }^{13}$

Diğer bir taraftan, bazı çalışmalarda da bağlanma dayanımı testlerinde iki aşamalı self-etch adeziv sistemlerin tek aşamalı self-etch adeziv sistemlere göre daha yüksek değerler verdiği gösterilmiştir. ${ }^{9,11}$ Harnirattisai ve ark., iki aşamalı sistemlerde ikinci aşamada uygulanan çözücü içermeyen hidrofobik bonding rezinler ile daha hidrofilik ve daha fazla su absorbe edebilen tek aşamalıların oluşturduğundan daha kuvvetli bir bağlantı ara yüz tabakası oluşturabileceğini belirtmişlerdir. ${ }^{11}$ Bizim çalışmamızın sonuçları ise yukarıdaki çalışmalar ile uyumludur.

Klinikte kullanılan materyallerin biyouyumluluğu son derece önemli bir kriterdir. Biyomateryallerin sitotoksisite değerlendirilmesi yapılırken çok çeşitli testler uygulanmaktadır. Bu testlere örnek olarak materyalin direk hücrelerle temas ettiği kontakt testler, direk temasın olmadığı indirekt testler ve kompozit materyalden salınan bazı maddelerin hücrelerle ekspoze olduğu ekstrakt testler verilebilir. Direkt temasın olmadığı indirekt kontakt testlerinde; materyal ve hücreler arasında milipor filtre, dentin dokusu veya agar tabakası gibi bir tabaka bulunur. Bu çalışmada agar overlay tekniği kullanılmıştır. Agar difüzyon deneyi yüksek yoğunluklu materyaller için uygundur. $\mathrm{Bu}$ teknikte direk kontak testlerinden farklı olarak hücreler ve materyal arasında ince bir tabaka besi ortamı içeren agar bulunur. Test materyalinin etrafında oluşan dekolarizasyon ve lizise uğramış hücre zonu değerlendirilir. ${ }^{6}$

Derin kavitelere bonding ajan uygulandığı zaman dentinin hemen altındaki pulpal hücrelerin bonding ajanın toksik etkisinden zarar görme intimali vardır. Dental adezivlerin derin kavitelere uygulandıkları zaman pulpal hücrelere sitotoksik etki oluşturacakları konusunda fikir birliği vardır.,14 Birçok çalışmada dental adezivlerin toksik etkileri gösterilmiştir; fakat bununla beraber pulpal problemlerin etyolojisi ve adezivlerin hücre siklusuna etkisi hala tam olarak açıklanabilmiş değildir. Bazı yazarlar bu toksisiteyi monomerlere bağlamışlardır. BisGMA, HEMA ve TEGDMA gibi monomerlerin orta derecede toksik olduğu rapor edilmiştir. ${ }^{15,16}$ Ancak 4-MET ve 4-META esaslı olan GB'un daha düşük sitotoksisite gösterdiği tespit edilmiştir. Şengün ver ark, dentin bağlayıc ajanları agar overlay ile değerlendirdikleri çalışmada GB ve CSE'nin orta düzeyde hücre lizisi gösterdiğini bildirmişlerdir. ${ }^{17}$

GB, içerisinde HEMA monomeri bulunmayan bir adeziv rezindir. CSE'nin içeriğindeki HEMA, Islanabilirliği artırır ve rezinin dentine penetrasyonunu kolaylaştırır. HEMA'nın metakrilat bazlı rezin kompozitlerden salınabildiği ve fizyolojik konsantrasyonların bile pulpa hücrelerini etkileyebildiği gösterilmiştir. ${ }^{18,19}$ Diğer taraftan, küçük hidrofilik bir monomer olan HEMA'nın sklerotik dentinden bile difüze olabildiği bildirilmiştir. ${ }^{20}$ Pawlowska ve ark ise HEMA'nın DNA hasarı, apoptozis ve hücre siklüsünde gecikme gibi zararlı biyolojik etkileri indükleyebileceğini bildirmişlerdir. ${ }^{21}$

Ancak bizim çalışmamızda L929 hücreleri üzerine bir agar bariyeri varlığında her iki dentin bağlayıcı ajanın da pozitif kontrol grubuna göre toksik olmadığı bulunmuştur. Daha önce yapılan pek çok araştırmada rezin modifiye cam iyonomer siman Vitrebond önemli derecede toksik bulunmuş ve pozitif kontrol materyali olarak kullanılmıştır. ${ }^{22,23} \mathrm{Bu}$ nedenle bu materyal bizim çalışmamızda da pozitif kontrol grubu olarak kullanılmıştır. Bizim verilere benzer olarak Korsuwannawong ve ark, hücre kültürü perfüzyon sistemi ile yaptıkları çalışmada Vitrebond'u pozitif kontrol grubu olarak kullanmışlar, GB ve CSE'nin buna göre sitotoksik olmadığını belirtmişlerdir. ${ }^{24}$

\section{SONUC}

$\mathrm{Bu}$ çalışmada kullanılan iki aşamalı self-etch sistem olan CSE'nin bağlanma dayanımı tek aşamalı self-etch olan GB'un bağlanma dayanımından daha yüksektir. Bununla beraber pozitif kontrol grubuna göre her iki adeziv sistem de sitotoksik bulunmamıştır. $\mathrm{Bu}$ sebeple klinik olarak daha uzun ömürlü restorasyonlar elde edebilmek için CSE, GB'a tercih edilebilir.

\section{KAYNAKLAR}

1. da Silva JM, Rodrigues JR, Camargo $\mathrm{CH}$, Fernandes VV Jr, Hiller KA, Schweikl H, Schmalz G. Effectiveness and biological compatibility of different generations of dentin adhesives. Clin Oral Investig 2014; 10.1007/s00784-013-1000-9.

2. Ülker $M$, Özcan $M$, Şengün $A$, Özer $F$, Belli S. Effect of Artificial Aging Regimens on the Performance of Self-Etching adhesives. J Biomed Mater Res Part B: 
Appl Biomater 2010; 93:175-84.

3. Schmalz G, Schuster U, Koch A, Schweikl H. Cytotoxicity of low pH dentin-bonding agents in a dentin barrier test in vitro. J Endod 2002; 28:18892.

4. Schmalz G. Use of cell cultures for toxicity testing of dental materials--advantages and limitations. J Dent. 1994;22:6-11.

5. Wataha JC. Principles of biocompatibility for dental practioners. J Prosth Dent. 2001;86:203-9.

6. Schmalz G. The agar overlay method. Int Endod J. 1988;21:59-66.

7. Schmalz G, Hiller KA ve Dörter-Aslan F. New developments in the filter test system for toxicity testing. J Mat Sci Mater Med. 1994;5:43-51.

8. Schmalz G. Biological proof of filling materials in the Gotting miniature pig-a pilot study. Dtsch Zahnarztl Z. 1981;36:357-60.

9. Eren D, Bektaş ÖÖ, Siso SH. Three different adhesive systems; three different bond strength test methods. Acta Odontol Scand 2013;71:978-83.

10. Reis A, Loguercio AD, Manso AP, Grande RH, SchiltzTaing $M$, Suh $B$, Chen $L$, Carvalho RM. Microtensile bond strengths for six 2-step and two 1step self-etch adhesive systems to enamel and dentin. Am J Den 2013; 26:44-50.

11. Harnırattısaı $C$, Roengrungreang $P$, Rangsısırıpaıboon $U$, Senawongse P. Shear and micro-shear bond strengths of four self-etching adhesives measured immediately and 24 hours after application. Dental Materials Journal 2012; 31: 779-87.

12. Yoshida $Y$, Nagakane K, Fukuda R, Nakayama $Y$, Okazaki M, Shintani H, Inoue S, Tagawa $Y$, Suzuki K, De Munck J, Van Meerbeek B. Comparative study on adhesive performance of functional monomers. J Dent Res 2004; 83: 454-8.

13. Chiaraputt S, Roongrujımek P, Sattabanasuk V, Panıch N, Harnırattısaı $C$ and Senawongse $P$. Biodegradation of all-in-one self-etch adhesive systems at the resin-dentin interface. Dental Materials Journal 2011; 30: 814-26.

14. Schweikl H, Spagnuolo G, Schmalz G. Genetic and cellular toxicology of dental resin monomers. J Dent Res 2006; 85: 870-7.

15. Koliniotou-Koumpia E, Papadimitriou S, Tziafas D, Pulpal responses after application of current adhesive systems to deep cavities. Clin Oral Invest 2007; 11:313-20.
16. Geurtsen W, Spahl W, Muller K, Leyhausen G, Aqueous extracts from dentin adhesives contain cytotoxic chemical. J Biomed Mater Res 1999; 48:772-7.

17. Şengün $A$, Botsalı $H E$, Öztürk B, Ulker $M$, Yalçın $M$, Hakkı SS. Agar-Overlay Metodu ile Dentin Bonding Ajanların Sitotoksisitelerinin Değerlendirilmesi. SÜ Diş Hek Fak Der, 2008; 17: 203-8.

18. Noda $M$, Wataha JC, Kaga $M$, Lockwood PE, Volkmann KR, Sano H. Components of dentinal adhesives modulate heat shock protein 72 expression in heat-stressed THP-1 human monocytes at sublethal concentrations. J Dent Res 2002;81:265-9.

19. Michelsen VB, Moe G, Skalevik R, Jensen E, Lygre H. Quantification of organic eluates from polymerized resin-based dental restorative materials by use of GC/MS. J Chromatogr B Analyt Technol Biomed Life Sci 2007; 850: 83-91.

20. Hamid A, Hume WR. Diffusion of resin monomers through human carious dentin in vitro. Endod Dent Traumatol 1997;13:1-5.

21. Pawlowska E, Poplawski T, Ksiazek D, Szczepanska J, Blasiak J. Genotoxicity and cytotoxicity of 2hydroxyethyl methacrylate. Mutat Res 2010; 696: 122-9.

22. Sengün A, Yalçın M, Ülker HE, Öztürk B, Hakkı SS. Cytotoxicity evaluation of dentin bonding agents by dentin barrier test on 3-dimensional pulp cells. Oral Surg Oral Med Oral Pathol Oral Radiol Endod 2011; 112: 83-8.

23. Vajrabhaya LO, Korsuwannawong S, Bosl C, Schmalz G, The cytotoxicity of self-etching primer bonding agents in vitro. Oral Surg Oral Med Oral Pathol Oral Radiol Endod 2009; 107: 86-90.

24. Korsuwannawong S, Srichan R, L Vajrabhaya. Cytotoxicity evaluation of self-etching dentine bonding agents in a cell culture perfusion condition. Eur J Dent 2012; 6: 408-14.

\section{Yazışma Adresi:}

Yrd. Doç. Dr. Hayriye Esra ÜLKER

Selçuk Üniversitesi, Dişhekimliği Fakültesi

Restoratif Diş Tedavisi Anabilim Dalı

Selçuklu, Konya, Türkiye

Tel: + 903322231244

Fax: + 903322410062

E-mail: botsalie@hotmail.com 